\title{
Spontaneous bilateral peripapillary, subhyaloid and vitreous hemorrhage with only minor platelet deficit in idiopathic thrombocytopenic purpura
}

This article was published in the following Dove Press journal:

International Medical Case Reports Journal

24 January 2014

Number of times this article has been viewed

\author{
Loo Wan-Wei ${ }^{1,2}$ \\ Tuan-Jaffar Tengku-Norina' \\ Ahmad-Alwi Azma-Azalina' \\ Abdul-Ghani Zulkifli' \\ Embong Zunaina ${ }^{2}$ \\ 'Department of Ophthalmology, \\ Hospital Raja Perempuan Zainab II, \\ Kota Bharu, ${ }^{2}$ Department of \\ Ophthalmology, School of Medical \\ Sciences, Health Campus, Universiti \\ Sains Malaysia, Kubang Kerian, \\ Kelantan, Malaysia
}

\begin{abstract}
A 45-year-old female with underlying idiopathic thrombocytopenic purpura (ITP) complained of acute onset of reduced vision and floaters, in both eyes, for 3 weeks. Visual acuity was 6/36 and 6/60 in the right eye and left eye, respectively. Ophthalmoscopy showed bilateral peripapillary, subhyaloid and vitreous hemorrhage. Hematological evaluation revealed moderate anemia (hemoglobin: $93 \mathrm{~g} / \mathrm{L}$ ) and mild thrombocytopenia (platelets: $120 \times 10^{9} / \mathrm{L}$ ). She was co-managed by a hematologist and ophthalmologists; she was treated medically. Follow-up care during the next 6 weeks revealed spontaneous, partially resolving hemorrhage, with improvement of visual acuity. The purpose of this case report is to highlight ophthalmic involvement of ITP in this patient, despite her only-mild thrombocytopenia, and her spontaneous recovery, despite her receiving only medical treatment.
\end{abstract}

Keywords: idiopathic thrombocytopenic purpura, subhyaloid hemorrhage, vitreous hemorrhage

\section{Introduction}

Idiopathic thrombocytopenic purpura (ITP) is an autoimmune disorder in which antibodies are directed against platelet surface antigens, causing a characteristic purpuric rash, or bleeding. ITP patients usually present with subcutaneous or mucosal bleeding. Ophthalmic involvement is exceptionally rare. ${ }^{1}$ We report a patient with ITP who developed spontaneous bilateral peripapillary, subhyaloid and vitreous hemorrhage with only minor platelet deficit.

\section{Case report}

A 45-year-old female with underlying ITP and diabetes mellitus presented to the Department of Ophthalmology, Hospital Raja Perempuan Zainab II, complaining of a sudden onset of reduced vision in both eyes, of about 3 weeks in duration. This was associated with floaters in both eyes. There was no history of trauma, intense aerobic exercise, heavy lifting, straining on the toilet, vomiting, coughing, or vigorous sexual activity. She had been diagnosed with ITP several years before, with initial presentation of menorrhagia. Examination revealed visual acuity of 6/36 and 6/60 in the right and left eyes, respectively. Anterior segment findings were unremarkable. Fundus examination showed bilateral peripapillary, subhyaloid and vitreous hemorrhage, which was more pronounced in the left eye (Figure 1). There were no diabetic retinopathy changes noted. Systemic examination did not reveal any petechiae, bruises, or mucosal bleeding.

Hematological evaluation was carried out. The patient's platelet count was $120 \times 10^{9} / \mathrm{L}$ (normal: 150-450×109/L); her hemoglobin count was $93 \mathrm{~g} / \mathrm{L}$ (normal: 120-160 g/L).
Correspondence: Embong Zunaina Department of Ophthalmology, School of Medical Sciences, Health Campus, Universiti Sains Malaysia, 16150 Kubang Kerian, Kelantan, Malaysia Tel +609767 6362

Fax +6097673370

Email zunaina@kb.usm.my 

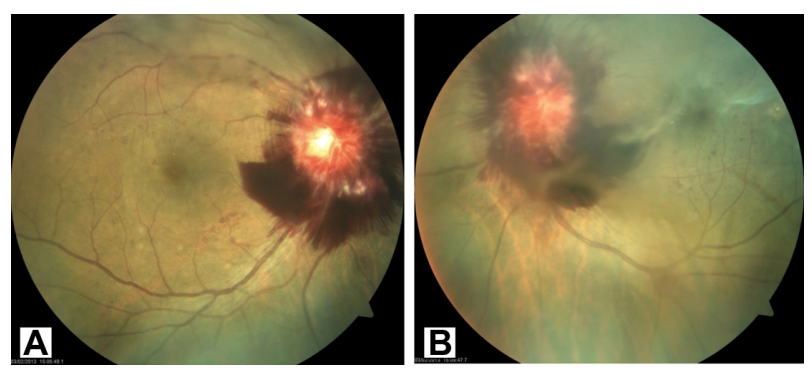

Figure I Fundus examination of both eyes showing peripapillary, subhyaloid and vitreous hemorrhage at initial presentation.

Notes: (A) right eye; (B) left eye.

Coagulation profile (prothrombin time and partial thromboplastin time) was normal.

After consultation by a hematologist, she was treated with oral prednisolone, starting dose of $50 \mathrm{mg}$ daily $(1 \mathrm{mg} / \mathrm{kg} /$ day $)$ for 1 week. Oral prednisolone treatment was then slowly tapered down over the next month. Review at 6 weeks showed spontaneous partial resolving of hemorrhages (Figure 2), and slight improvement of vision (to 6/24 - both eyes). It was recommended to the patient that she undergo left eye vitrectomy (in view of the fact the subhyaloid hemorrhage was just adjacent to the macula), but the patient has not yet consented to the operation.

\section{Discussion}

ITP is an autoimmune hematological disease wherein circulating antibodies direct activity against host platelet surface antigens causing platelet destruction, thereby resulting in reduced platelet counts and subsequent complications of bleeding. The common presentations of ITP are bleeding from the skin, mucous membrane, gastrointestinal tract, central nervous system, and vagina., ${ }^{2,3}$ There are no large case series on the spectrum of findings on ITP in eyes; mostly, these are single-case reports. Ophthalmic manifestations associated with ITP reported include vitreous hemorrhage, ${ }^{4}$ subconjunctival hemorrhage, ${ }^{5}$ massive subretinal hemorrhage
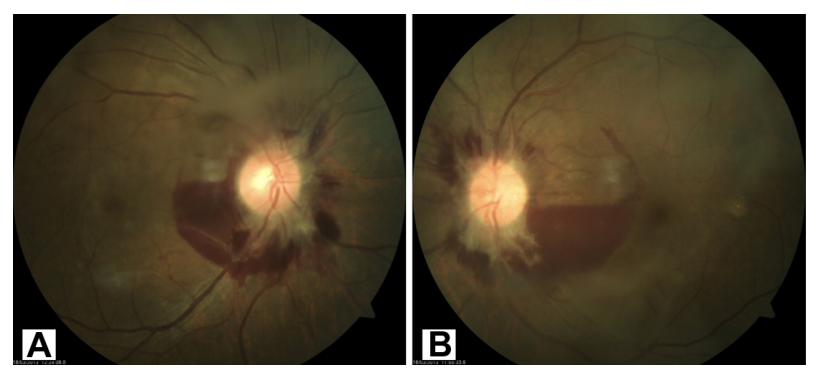

Figure 2 Fundus examination of both eyes showing spontaneous partially resolved hemorrhage after 6 weeks.

Notes: (A) right eye; (B) left eye. with life-threatening intracranial hemorrhage, ${ }^{6}$ and vitreoretinal hemorrhages..$^{7-9}$

Majji et al, ${ }^{7}$ Okuda et $a l,{ }^{8}$ and Pathengay et $a l^{9}$ have reported similar posterior segment findings in their case reports, which are also seen in our patient. It has been reported by Rubenstein et al that there is a high incidence of retinal hemorrhage in patients with severe anemia $(<80 \mathrm{~g} / \mathrm{L})$ and severe thrombocytopenia $\left(<50 \times 10^{9} / \mathrm{L}\right)$, but a much lower frequency in anemic patients without thrombocytopenia. ${ }^{10}$ However, this is not what we had observed from this patient, who had only mild thrombocytopenia $\left(120 \times 10^{9} / \mathrm{L}\right)$ and moderate anemia ( $93 \mathrm{~g} / \mathrm{L}$ ) when she presented with ocular symptoms, in contrast to severe thrombocytopenia in other case reports $\left(12 \times 10^{9} / \mathrm{L}\right.$ by Majji et al; $42 \times 10^{9} / \mathrm{L}$ by Pathengay et al; and $<2 \times 10^{9} / \mathrm{L}$ by Okuda et al). ${ }^{7-9}$ Carraro et al demonstrated that retinopathy was closely associated with the conditions of severe anemia and severe, or very severe, thrombocytopenia. ${ }^{11}$

This patient was recommended to undergo left eye vitrectomy, to evacuate the subhyaloid hemorrhage that was threatening the macula; but, she refused any surgical intervention. Her condition improved progressively, after she started on medical treatment. Similar findings were seen in Majji et al's patient, in whom complete resolution of hemorrhages was noted after the patient had been managed through only systemic factors, without any invasive procedure. ${ }^{7}$ Nevertheless, vitrectomy can be beneficial for massive vitreoretinal hemorrhages. ${ }^{8}$ Okuda et al performed vitrectomy for a patient with ITP who presented with massive bilateral vitreoretinal hemorrhage. The patient's vision (better eye) improved from $6 / 90$ to $6 / 30$ after surgery. Vision in the other eye remained poor, due to the presence of submacular fibrosis. ${ }^{4}$

\section{Conclusion}

ITP usually presents with skin manifestations, such as bruises or mucosal bleeding. Ophthalmic involvement is rare. Unexplained and suspicious posterior segment hemorrhage should be evaluated for ITP causation.

\section{Disclosure}

The authors report that they have no conflicts of interest in this work.

\section{References}

1. Holt JM, Gordon-Smith EC. Retinal abnormalities in diseases of the blood. Br J Ophthalmol. 1969;53:145-160.

2. DiFino SM, Lachant NA, Kirshner JJ, Gottlieb AJ. Adult idiopathic thrombocytopenic purpura in adults. Long term results in a series of 41 patients. Ann Clin Res. 1978;10:83-86. 
3. Levine SP. Thrombocytopenia caused by immunologic platelet destruction. In: Lee GR, et al, editors. Wintrobe's Clinical Hematology. 10th ed. Philadelphia, PA: Williams Wilkins. 1993:1583-1611.

4. Turaka K, Shields CL, Bianciotto C, Shields JA. Vitreous hemorrhage as the initial manifestation of idiopathic thrombocytopenic purpura. Retin Cases Brief Rep. 2012;6:16-18.

5. Sodhi PK, Jose R. Subconjunctival hemorrhage: the first presenting clinical feature of idiopathic thrombocytopenic purpura. Jpn $J$ Ophthalmol. 2003;47:316-318.

6. Shah PA, Yang SS, Fung WE. Idiopathic thrombocytopenic purpura with massive subretinal hemorrhage. Arch Ophthalmol. 2005;123:1612-1613.

7. Majji AB, Bhatia K, Mathai A. Spontaneous bilateral peripapillary, subhyaloid and vitreous hemorrhage with severe anemia secondary to idiopathic thrombocytopenic purpura. Indian J Ophthalmol. 2010;58:234-236.
8. Okuda A, Inoue M, Shinoda K, Tsubota K. Massive bilateral vitreoretinal hemorrhage in patient with chronic refractory idiopathic thrombocytopenic purpura. Graefes Arch Clin Exp Ophthalmol. 2005;243:1190-1193.

9. Pathengay A, Das MK, Shah GY. Spontaneous bilateral peripapillary, subhyaloid and vitreous hemorrhage with severe anemia secondary to idiopathic thrombocytopenic purpura. Indian J Ophthalmol. 2011;59: 409-411.

10. Rubenstein R, Yanoff M, Albert D. Thrombocytopenia, anemia and retinal hemorrhage. Am J Ophthalmol. 1968;65:435-440.

11. Carraro MC, Rossetti L, Gerli GC. Prevalence of retinopathy in patients with anemia or thrombocytopenia. Eur J Haematol. 2001;67: $238-244$.

\section{Publish your work in this journal}

The International Medical Case Reports Journal is an international, peer-reviewed open-access journal publishing original case reports from all medical specialties. Previously unpublished medical posters are also accepted relating to any area of clinical or preclinical science. Submissions should not normally exceed 2,000 words or
4 published pages including figures, diagrams and references. The manuscript management system is completely online and includes a very quick and fair peer-review system, which is all easy to use. Visit http://www.dovepress.com/testimonials.php to read real quotes from published authors.

Submit your manuscript here: http://www.dovepress.com/international-medical-case-reports-journal-journal 